\title{
Embryonic amygdalar transplants in adult rats with motor cortex lesions: a molecular and electrophysiological
} analysis

\section{Lydia Jiménez-Díaz 1,2,3 *, Mauricio O. Nava-Mesa ${ }^{2,3}$, Margarita Herediaa, ${ }^{2,3}$,Adelaida S. Riolobos ${ }^{2,3}$, Marcelo Gómez-Álvarez $z^{2,3}$, José María Criado ${ }^{2,3}$, Antonio de la Fuente ${ }^{2,3}$, Javier Yajeya ${ }^{2,3}$ and Juan D. Navarro-López ${ }^{1,2,3}$ *}

${ }^{1}$ Laboratorio de Neurofisiología, Facultad de Medicina de Ciudad Real, Universidad de Castilla-La Mancha, Castilla-La Mancha, Spain

2 Instituto de Neurociencias de Castilla y León, Universidad de Salamanca, Salamanca, Spain

${ }^{3}$ Departamento de Fisiología y Farmacología, Facultad de Medicina, Universidad de Salamanca, Salamanca, Spain

\section{Edited by:}

Leif A. Havton, UCLA

Neurorehabilitation and Research

Center, USA

\section{Reviewed by:}

Mattias Sköld, Uppsala University, Sweden

Brian J. Cummings, University of California Irvine, USA

\section{*Correspondence}

Lydia Jiménez-Díaz and

Juan D. Navarro-López, Área de Fisiología, Facultad de Medicina de Ciudad Real, Universidad de Castilla-La Mancha, Paseo de Moledores s/n, 13071-Ciudad Real, Spain.

e-mail:Iydia.jimenez@uclm.es; juan.navarro@uclm.es
Transplants of embryonic nervous tissue ameliorate motor deficits induced by motor cortex lesions in adult animals. Restoration of lost brain functions has been recently shown in grafts of homotopic cortical origin, to be associated with a functional integration of the transplant after development of reciprocal host-graft connections. Nevertheless little is known about physiological properties or gene expression profiles of cortical implants with functional restorative capacity but no cortical origin. In this study, we show molecular and electrophysiological evidence supporting the functional development and integration of heterotopic transplants of embryonic amygdalar tissue placed into pre-lesioned motor cortex of adult rats. Grafts were analyzed 3 months post-transplantation. Using reverse transcriptase quantitative polymerase chain reaction, we found that key glutamatergic, GABAergic, and muscarinic receptors transcripts were expressed at different quantitative levels both in grafted and host tissues, but were all continuously present in the graft. Parallel sharp electrode recordings of grafted neurons in brain slices showed a regular firing pattern of transplanted neurons similar to host amygdalar pyramidal neurons. Synaptic connections from the adjacent host cortex on grafted neurons were electrophysiologically investigated and confirmed our molecular results. Taken together, our findings indicate that grafted neurons from a non-cortical, non-motor-related, but ontogenetical similar source, not only received functionally effective contacts from the adjacent motor cortex, but also developed electrophysiological and gene expression patterns comparable to host pyramidal neurons; suggesting an interesting tool for the field of neural repair and donor tissue in adults.

Keywords: transplantation, heterotopic amygdalar graft, electrophysiology, RT-qPCR, neurotransmitter receptors, adult rat

\section{INTRODUCTION}

It is believed that the function of a neural system results from the high balance and level of specificity of its synaptic connections. The adult brain has a limited capacity for self-repair after neuronal loss caused by trauma or disease. Traumatic alterations of the axonal wiring, such as those happening in cortical lesions, immediately produce a permanent functional impairment which leads to behavioral deficits and have severe anatomical consequences (Sorensen et al., 1989; Plumet et al., 1993; Gaillard et al., 1998; Riolobos et al., 2001; Chen et al., 2002). Embryonic tissue transplanted into the damaged cortex of adult rats has shown successful survival and establishment of reciprocal connections between the host and grafted tissue (Castro et al., 1988; Xu et al., 1991; Plumet et al., 1993; Roger and Ebrahimi-Gaillard, 1994; Frappe et al., 1999; Chen et al., 2002; Gaillard et al., 2007; Gaillard and Domballe, 2008; Santos-Torres et al., 2009) and has lead to behavioral graft-dependent recovery (Labbe et al., 1983; Fernandez-Ruiz et al., 1991; Plumet et al., 1991; Riolobos et al., 2001; Heredia et al., 2004).
Therefore, certain level of adequate axonal wiring seems to be necessary for the reconstruction of cortical circuitry and restoration of lost brain function.

Previous studies have demonstrated that homotopic cortical cells transplanted into damaged host adult motor cortex develop into normal cortical neurons and establish functional effective host-graft interconnections (Santos-Torres et al., 2009), suggesting that both events could underlie functional (behavioral) graftdependent recovery of motor deficits (Plumet et al., 1993; Riolobos et al., 2001). It has also been observed that heterotopic transplants of amygdalar embryonic tissue (a non-cortical and non-motorrelated tissue) grafted in adult rats following motor cortex lesion induce the same level of behavioral graft-dependent recovery as homotopic grafts (Heredia et al., 2004), suggesting a similar functional integration of the grafted tissue.

To further the understanding of graft integration and behavioral restoration, numerous immunohistochemical and retrograde axonal tracing studies in the adult brain have been undertaken to 
describe grafted neurons phenotype and determine the nature of graft-host connectivity (Escobar et al., 1989; Castro et al., 1991; Heredia et al., 2004; Thompson et al., 2005; Gaillard et al., 2007; Santos-Torres et al., 2009). However, to our knowledge, molecular characterization of heterotopically transplanted cells with functional restorative capacity has remained virtually unexplored ( $\mathrm{Su}$ et al., 2009), and electrophysiological studies of how non-cortical grafted neurons are effectively integrated in the adult host brain have also been scarce (Segal and Azmitia, 1986; Castro et al., 1991; Senatorov et al., 1991; Zhou et al., 1998).

The purpose of the present study was to characterize the molecular and functional properties of embryonic grafted amygdaloid cells transplanted into motor cortical locations, by carrying out gene expression studies in parallel with electrophysiological recordings from grafts of amygdalar embryonic tissue implanted into host pre-lesioned motor cortex of adult rats.

Behavioral motor restorative capacity of heterotopic amygdalar transplants into lesioned motor cortex (Heredia et al., 2004) together with the fact that amygdaloid and motor cortical structures share a common ontogenetic origin which might suggest that reestablishment of connections between host cortex and transplanted tissue could be facilitated (Puelles et al., 2000; Medina et al., 2004; Garcia-Lopez et al., 2008) made amygdalar tissue an excellent grafting source candidate.

Besides analyzing astrogliosis induced by graft integration, we provide quantification of the relative mRNA levels of glutamatergic, GABAergic, and muscarinic receptors in the graft and host tissues by reverse transcriptase quantitative polymerase chain reaction (RT-qPCR), and electrophysiological analysis of transplanted neurons and their synaptic afferents coming from host adjacent tissue. Three months after transplantation expression patterns of the receptors were similar in grafted and host control tissues (amygdaloid complex and contralateral motor cortex), and transplanted neurons exhibited normal electrophysiological properties as well as functional synaptic connections coming from the host brain. Our findings show that heterotopic amygdaloid transplanted cells are successfully integrated within the host ontogenetically related cortical tissue and provide a molecular and functional characterization of this integration that could underlie functional recovery induced by this type of transplants.

\section{MATERIALS AND METHODS}

All experiments were carried out in accordance with the animal care guidelines of the European Communities Council (86/609/ECC). Twenty three male Wistar rats (Criffa Laboratories, France) were used, aged 3 months before surgery. Very briefly, animals were unilaterally lesioned in the motor cortex by aspiration as previously described (Riolobos et al., 2001; Santos-Torres et al., 2009). Seven days after lesion the animals were unilaterally transplanted with donor amygdaloid tissue obtained from 15-day-old rat embryos from pregnant Wistar rats (at 08:00 h on embryonic day 15, E15; sperm-positive vaginal smear DATE=E0). Heterotopic transplantations of amygdaloid tissue were performed as previously described for homotopic cortical transplants (Riolobos et al., 2001; Santos-Torres et al., 2009). Briefly, donor's skull was cut at the midline and peeled back, the brain was dissected out and the meninges removed in a dish with sterile glucose-saline.
Donor embryonic tissue was set up while the host was being prepared to receive it. Two solid pieces of the embryonic amygdala of approximately $1 \mathrm{~mm}^{3}$ each were taken out from the embryo and located at the bottom of the single motor cortex cavity at the host animal. The cavity containing the transplant was filled up with a piece of gelfoam soaked in glucose-saline and the skin sutured. All experiments were performed 3-4 months after transplantation, all grafts $(100 \%)$ grew and filled the lesion cavity after this period, and where therefore included in the study.

\section{IMMUNOLABELING}

In order to investigate glial scar of the graft, Nissl cresyl fast violet and glial fibrillary acidic protein (GFAP) immunohistological stainings were performed (Figure 1). Deeply anesthetized animals $(n=5)$ were perfused through the ascending aorta with a wash solution ( $2 \%$ dextran in phosphate buffer, $\mathrm{PB} 0.1 \mathrm{M}, \mathrm{pH}$ 7.4) at room temperature followed by a $4 \%$ paraformaldehyde in $\mathrm{PB}$ solution. Brains were then removed from the skulls and post-fixed in the same fixative $\left(4^{\circ} \mathrm{C}\right)$. Coronal sections were cut at $40 \mu \mathrm{m}$, mounted and incubated with the primary antibody solution. A polyclonal rabbit anti-GFAP antibody (Dako; 1:1000) was used to visualize astroglia. A standard ABC (Vector Laboratories, Burlingame, CA, USA) routine was then followed. The reaction product was visualized with a solution of diaminobenzidine and hydrogen peroxide (Figure 1). Separate sections were stained with cresyl fast violet to determine cortical and transplant cytoarchitecture.

\section{REVERSE TRANSCRIPTASE QUANTITATIVE POLYMERASE CHAIN REACTION}

Neurotransmitter receptor gene expression levels were quantified in transplants using RT-qPCR. For tissue collection and RNA preparation, unilateral grafted rats $(n=6)$ were decapitated and the brains were rapidly removed. Three tissue blocks corresponding to the core of the graft and size-equivalent pieces of both amygdala and contralateral motor cortex were dissected out from each brain under visual control (using a stereomicroscope, Leica, Germany; Figures 1A-C). Graft boundaries were very evident facilitating the dissection procedure. Care was taken not to take any cortical host tissue while the graft-piece was being dissected (briefly, graft was extracted using a micro-spoon, micro-scissors were then used to release meninges, and a sharp blade allowed dissection of the graft core; Figure 1C). Total RNA was extracted from homogenized tissue samples using TRIZOL (Invitrogen, USA). RNA quality was assessed on a RNA 6000 NanoLabChip (Agilent, USA) and Agilent 2100 Bioanalyzer. Equal amounts $(0.4 \mu \mathrm{g})$ of total RNA were reversed transcribed using random non-amers (Sigma, UK), oligo(dT) 15 primers (Promega, USA) and Superscript TM III RT (Invitrogen, USA). Real-time PCR reactions were performed with ABI PRISM 7000 Sequence Detection System (Applied Biosystems, Spain) using Power SYBR Green PCR Master Mix (Applied Biosystems, Spain) with each gene-specific primers (genes coding for GluR1, GluR2, NR1, NR2A, NR2B, GABAa $\alpha 1$ and GABAa $\alpha 2$ subunits, and $M 1$ receptor (M1R) were studied; see below for primer sequences). Control cDNA samples (obtained without transcriptase) were always included, as well as samples without any cDNA template. Efficiencies of PCR 


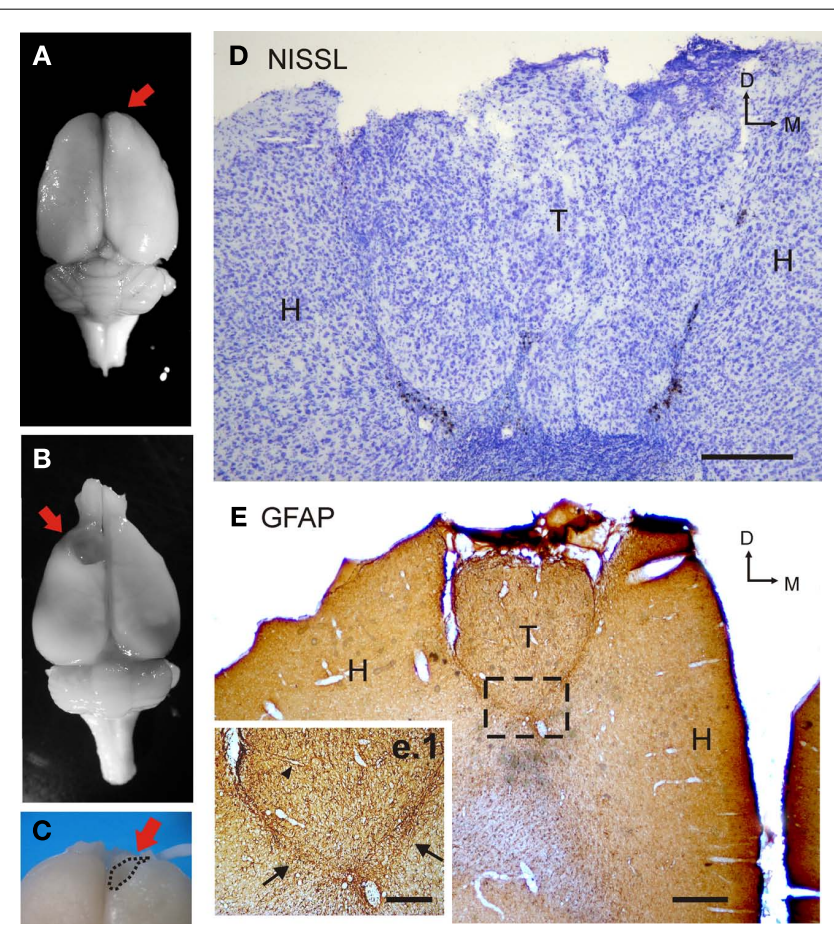

FIGURE 1 | Immunolabeling of transplanted cells. (A) Photograph of a transplanted rat brain. The red arrow indicates the location of the heterotopic cortical transplant of embryonic amygdalar tissue. (B) Photograph of a grafted rat brain after transplant dissection. Note the cavity left by the graft (red arrow). (C) Details of the dissection procedure for graft separation from host tissue. (D) Photomicrograph of Nissl staining in a coronal section through a heterotopic cortical transplant of embryonic amygdalar tissue. Note the clustered distribution of grafted cells. (E) Photomicrograph of GFAP immunolabeling in a coronal section through an amygdalar transplant placed heterotopically in motor cortical location. Square (e.1) shows grafted GFAP-immunoreactive cells in the host and the transplant at higher magnification. Arrows indicate the notable glial scar. Black triangle indicates a partially stained vessel in the graft [scale bars: (A), $250 \mu \mathrm{m}$; (B), $500 \mu \mathrm{m}$; (b.1), $200 \mu \mathrm{m}$; H, host; T, transplant; L, lateral].

(E) were calculated for each gene using serial dilutions. Reactions were performed in triplicate for three to four biological replicates, and threshold cycle (CT) values were normalized to $\beta$-actin gene expression. Changes in gene expression levels were quantified according to Pfaffl (2001) using CT and E values of target and reference genes. The ratio of the relative expression of target genes to $\beta$-actin was calculated by using the formula: ratio $=\mathrm{E}_{\text {target }}^{\Delta \mathrm{CT} \text { target (control-transplant) }} / \mathrm{E}_{\beta}^{\Delta \mathrm{CT} \beta \text { actin }}$ (control-transplant) At the end of the qPCR, a melting curve analysis was run to determine the specificity of the products.

PCR primer sequences were replicated from published information (GABAa $\alpha 1$, GABAa 2 (Picard et al., 2008), M1R (Malkoff et al., 2008), or designed from sequence databases (NCBI, USA) using Sigma Genosys Probe Design Service (Sigma, UK). Sequences and accession numbers are detailed in Table $\mathbf{1 .}$

\section{ELECTROPHYSIOLOGICAL RECORDINGS IN BRAIN SLICES}

For electrophysiological characterization of the transplanted neurons in vitro, animals $(n=12)$ were deeply anesthetized with
Table 1 | Sequences of primers for RT-qPCR.

\begin{tabular}{|c|c|c|}
\hline Gene & Primer sequence & $\begin{array}{l}\text { Gene bank } \\
\text { number }\end{array}$ \\
\hline$\beta$-Actin & $\begin{array}{l}\text { F: 5'-AGCCATGTACGTAGCCATCC-3' } \\
\text { R: 5'-ACCCTCATAGATGGGCACAG-3' }\end{array}$ & NM_031144 \\
\hline GluR1 & $\begin{array}{l}\text { F: 5'-TTCTGCACCGGTTTTCTAGG-3' } \\
\text { R: 5'-CGCATGTTCCTGTGATTGTT-3' }\end{array}$ & NM_031608 \\
\hline GluR2 & $\begin{array}{l}\text { F: 5'-CGGCAGCTCAGCTAAAAACT-3' } \\
\text { R: 5'-TTGTAGCTGGTGGCTGTTGA-3' }\end{array}$ & NM_017261 \\
\hline$N R 1$ & $\begin{array}{l}\text { F: 5'-CAGCCGTGAACGTGTGGAG-3' } \\
\text { R: 5'-TGCTCTACCACTCTTTCTATCC-3' }\end{array}$ & NM_017010 \\
\hline NR2A & $\begin{array}{l}\text { F: } \text { 5'-CAGTGATGTGTATATTTCAGAGCATG } \\
\text { TTA-3' } \\
\text { R: 5'-ACACTCGTCTATTGCTGCAGGAA-3' }\end{array}$ & NM_012573 \\
\hline$N R 2 B$ & $\begin{array}{l}\text { F: 5'-TCCGTCTTTCTTATGTGGATATGC-3' } \\
\text { R: 5'-CCTCTAGGCGGACAGATTAAGG-3' }\end{array}$ & NM_012574 \\
\hline GABAa $\alpha 1$ & $\begin{array}{l}\text { F: 5'-TTTGGAGTGACGACCG-3' } \\
\text { R: 5'-CTAATCAGAGCCGAGAA-3' }\end{array}$ & NM_183326 \\
\hline GABAa 2 & $\begin{array}{l}\text { F: 5'-TGGTGCTGGCTAACAT-3' } \\
\text { R: 5'-GTCCTGGTCTAAGACGAT-3' }\end{array}$ & NM_001135779 \\
\hline$M 1 R$ & $\begin{array}{l}\text { F: 5'-GACCTCATCATTGGCACCTT-3' } \\
\text { R: 5'-GGTCAAAGCTGATGAGCAGA-3' }\end{array}$ & NM_080773 \\
\hline
\end{tabular}

F, forward; $R$, reverse.

halothane, decapitated, and standard slicing procedures were performed (see details in Yajeya et al., 1997; Santos-Torres et al., 2009). Sharp electrode recordings were obtained from neurons in coronal slices ( $n=3-5$ per animal) including the heterotopic graft or the basolateral amygdaloid complex. To morphologically identify the neurons and recording sites in the grafts, some neurons were filled with $2 \%$ biocytin (Sigma, UK) in a potassium acetate solution $(2 \mathrm{M})$ at the end of electrophysiological recordings as previously described (Santos-Torres et al., 2009).

All chemicals used in this study were applied by perfusion in artificial cerebrospinal fluid (ACSF). CNQX and APV (Tocris, Spain), AMPA and NMDA receptor antagonists respectively, were added to remove the excitatory glutamatergic responses and atropine sulfate, a muscarinic antagonist (Sigma, UK), was used to study the presence of functional cholinergic receptors. Action potentials and synaptic currents were averaged $(n \geq 5)$ and expressed here as mean \pm SEM.

Statistical analysis of both, molecular and electrophysiological collected data, was performed using two-tailed Student's $t$ test or ANOVA when appropriate. Statistical significance was determined at a level of $p \leq 0.05$.

\section{RESULTS}

\section{IMMUNOSTAINING}

In order to investigate the cytoarchitecture of the graft and the cellular response of the host to the lesion, Nissl staining and GFAP immunohistological analysis were performed (Figures 1D,E). Amygdalar transplants cytoarchitecture was formed by cellular clusters, as previously described for homotopic cortical grafts (Riolobos et al., 2001), and no cortex stratification was observed (Figure 1D). Transplants included cells with different sizes and 
morphologies. On the other hand, high GFAP expression is one of most distinct characteristics of astrogliosis and therefore, it has been previously reported to be used to study glial scaring (Soares and McIntosh, 1991). As shown in Figure 1E, in heterotopic transplants, graft-host interface was quite notable, showing a very evident glial scar.

\section{GENE EXPRESSION ANALYSIS}

To determine whether the expression of neurotransmitter receptors in heterotopic amygdalar transplants was similar to that in cortical and/or amygdaloid host tissues, eight receptor-related transcripts were quantified by RT-qPCR. To monitor glutamatergic, GABAergic, and cholinergic neurotransmission, expression levels of transcripts encoding for (i) the major subunits of ionotropic NMDA (NR1, NR2A, and NR2B) and AMPA (GluR2 and GluR1) glutamatergic receptors, (ii) $\alpha 1$ and $\alpha 2$ subunits of the ionotropic GABAa receptor, and (iii) muscarinic M1 receptor, were investigated in the three brain regions of grafted rats. As shown in Figure 2 the same qualitative mRNA expression pattern was found within the graft and both control regions (contralateral cortex and amygdaloid complex), as the eight receptor subunits and subtypes studied were detected in the three regions analyzed. However, quantification of relative mRNA levels of the eight transcripts showed that all but GluR1 and GABAa $\alpha 2$ mRNAs were expressed at significant lower levels in grafted tissue (30-80\% less expression) than in contralateral motor cortex (Figure 2A; Glu R1: $t_{(5)}=-1.6, p=0.19$; GluR2: $t_{(5)}=-3.9, p=0.01$; NR1: $t_{(5)}=-3.8, \quad p=0.01 ; \quad \mathrm{NR} 2 \mathrm{~A}: \quad t_{(5)}=-5.8, \quad p=0.002$; NR2B: $t_{(5)}=-3.06, p=0.028$; GABAa $\alpha 1: t_{(5)}=-3.9, p=0.026$; GABAa $\left.\alpha 2: t_{(5)}=-1.9, p=0.11 ; \mathrm{M} 1: t_{(5)}=-4.7, p=0.005\right)$ or the amygdaloid complex (Figure 2B; Glu R1: $t_{(5)}=-1.7, p=0.14$; GluR2: $t_{(5)}=-2.6, p=0.04$; NR1: $t_{(5)}=-3.4, p=0.01$; NR2A: $t_{(5)}=-5.2, p=0.004$; NR2B: $t_{(5)}=-2.6, p=0.049$; GABAa $\alpha 1$ : $t_{(5)}=-2.8, p=0.038 ; \mathrm{GABAa} \alpha 2: t_{(5)}=-0.24, p=0.82 ; \mathrm{M} 1$ : $\left.t_{(5)}=-2.9, p=0.05\right)$.

\section{INTRINSIC PROPERTIES OF GRAFTED NEURONS}

Sharp electrode recordings were obtained from neurons $(n=20)$ in adult grafted rat brain slices. Resting membrane potential (RMP), input resistance (Ri), membrane time constant, and firing threshold were measured. Recorded cells in the transplant were compared with pyramidal basolateral amygdaloid neurons $(n=8)$ of the same preparation. As detailed below, recorded cells in the graft were later on morphologically identified as pyramidal-like neurons using biocytin-labeling techniques.

The direct activation of grafted neurons by supra-threshold depolarizing current injection (0.1-0.5 nA) defined a regular firing pattern of discharge $(n=10$, Figure $3 \mathrm{C})$, presenting action potentials or a train of spikes with a very slow adaptation (Figure 3C). No differences were found between any of the evaluated parameters in grafted cells (RMP, Ri, mean membrane time constant, and threshold potential) when compared to basolateral amygdaloid neurons [transplant vs. amygdala control: RMP, $-72.1 \pm 1.2$ vs. $-71.3 \pm 3.1 \mathrm{mV}(p=0.81)$; Ri, $98.9 \pm 19.4$ vs. $102.1 \pm 10.4 \mathrm{M} \Omega(p=0.88)$; mean membrane time constant, $18.7 \pm 5.9$ vs. $24.3 \pm 4.1 \mathrm{~ms}(p=0.45)$; threshold potential, $52.3 \pm 2.6$ vs. $-54.3 \pm 2.8 \mathrm{mV}(p=0.60)]$. Some of the grafted

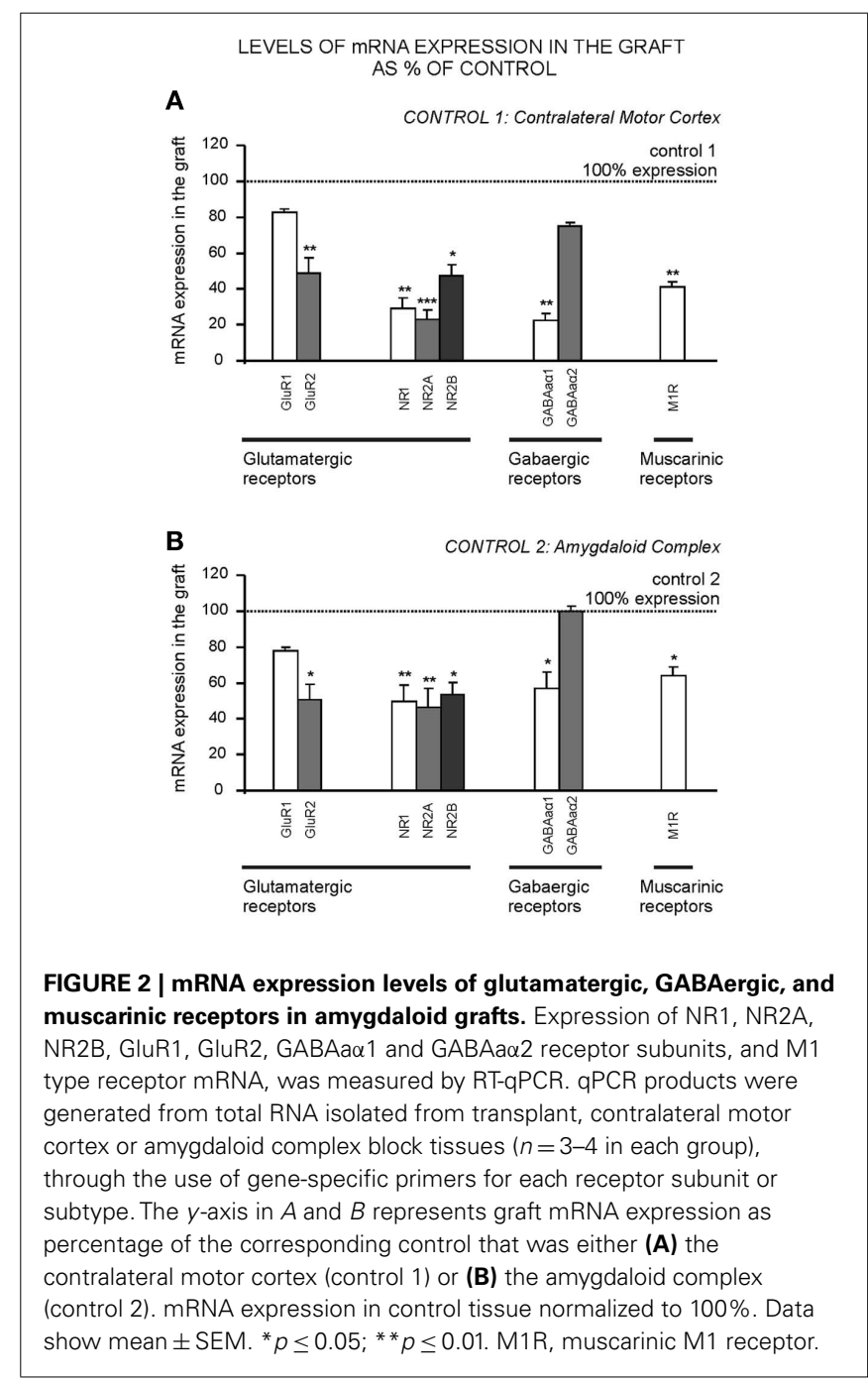

neurons $(n=10)$ presented spontaneous action potentials at RMP values, as well as basolateral amygdaloid neurons but no significant differences in measured values were found (Figure 3D; transplanted vs. amygdalar cells: spike amplitude, $69.9 \pm 1.2$ vs. $73.9 \pm 2.1 \mathrm{mV}(p=0.12)$; rise time, $0.40 \pm 0.11$ vs. $0.32 \pm 0.02 \mathrm{~ms}$ $(p=0.56)$; decay time, $1.5 \pm 0.09$ vs. $1.2 \pm 0.2 \mathrm{~ms}(p=0.15)$; half width, $3.5 \pm 0.17$ vs. $2.2 \pm 1.2 \mathrm{~ms}(p=0.21)$.

\section{EVOKED SYNAPTIC RESPONSES IN THE TRANSPLANT}

In order to investigate whether connections between adjacent host cortex and neurons in the graft existed, electrical stimuli were applied in the host cortex $(n=10)$, at a distance of $1 \mathrm{~mm}$ from the transplant limits (Figure 3A). Excitatory postsynaptic potentials (EPSP) were evoked in all cases indicating successful afferent neurotransmission on transplanted neurons. This synapse presented paired pulse facilitation $[n=7 ; S 1$ vs. $S 2$ mean values for: amplitude, $6.3 \pm 1.2$ vs. $8.6 \pm 1.6 \mathrm{mV}(p=0.27)$; duration, $31.8 \pm 10.6$ vs. $42.6 \pm 18.4 \mathrm{~ms}(p=0.62)$; rise time, $8.7 \pm 1.6$ vs. $10.2 \pm 1.3 \mathrm{~ms}$ $(p=0.48)$; decay time, $35.8 \pm 7.6$ vs. $38.9 \pm 3.1 \mathrm{~ms}(p=0.71)$; and half width, $8.5 \pm 2.9$ vs. $10.2 \pm 1.2 \mathrm{~ms}(p=0.59)]$ as shown in Figure 3E. The EPSP amplitude showed a graded amplitude 

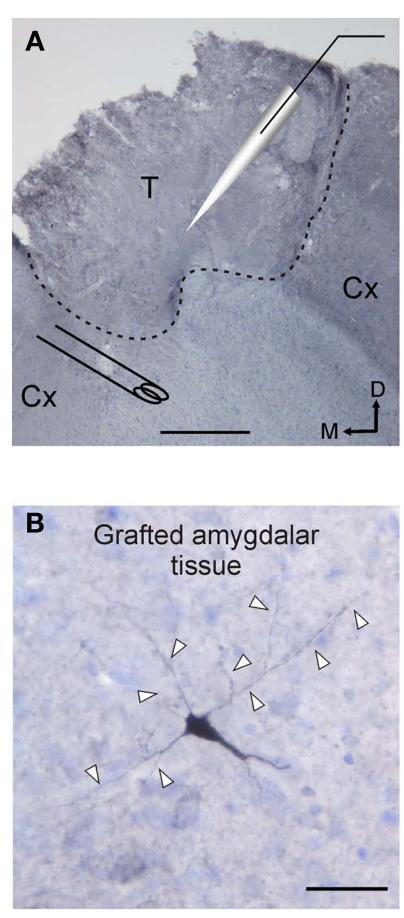

FIGURE 3 | Electrophysiological properties of amygdalar grafted neurons and characterization of host-graft connections.

(A) Experimental design. Photomicrograph of a coronal section through a amygdaloid transplant into motor cortex stained with cresyl violet. Schematic location of recording and stimulating electrodes is shown. Recordings were made using current clamp technique. Stimuli were applied to the adjacent host cortex. Dashed line indicates transplant edge. T, transplant; Cx: adjacent host cortex. Scale bar $250 \mu \mathrm{m}$. M, medial; D, dorsal. (B) A photomicrograph of a 40- $\mu \mathrm{m}$-thick slice showing a reconstruction of a transplanted neuron labeled with biocytin after intracellular recording. Note the pyramidal morphology of the neuron. Arrow heads indicate neural processes. Scale bar $50 \mu \mathrm{m}$. (C) Current clamp responses of transplanted

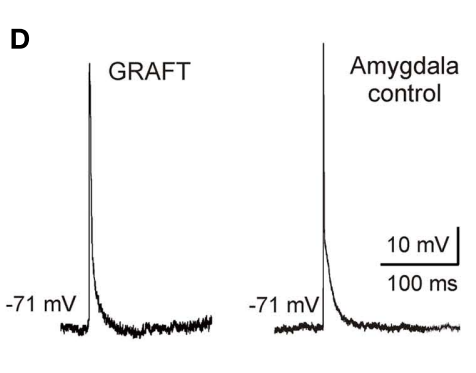

$\mathbf{F}$
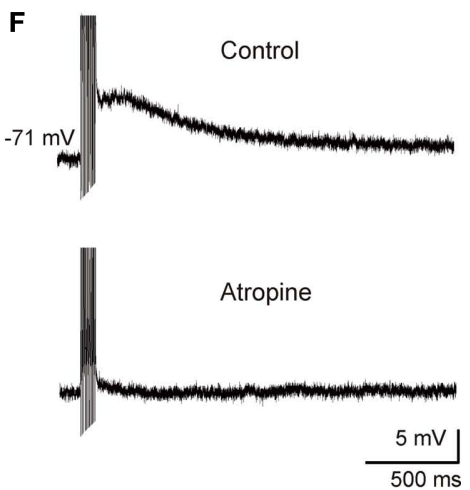

nature, depending on stimulus intensity and on RMP, suggesting a monosynaptic nature (data not shown). Synaptic responses could be removed $(n=5)$ by CNQX $(10 \mu \mathrm{M})$ and APV $(50 \mu \mathrm{M})$ suggesting that they were mediated by glutamic acid acting on ionotropic receptors (Figure 3E). Finally, train stimulation $(200 \mathrm{~Hz}, 100 \mathrm{~ms})$ of the adjacent cortex induced a sustained depolarization of neurons recorded in the graft $(n=5)$ exceeding the end of the train by hundreds of milliseconds (amplitude of $9.8 \pm 3.1 \mathrm{mV}$ and a duration of $1.9 \pm 0.8 \mathrm{~s}$ ). This response presented muscarinic nature since atropine perfusion $(1 \mu \mathrm{M})$ was able to abolish it (Figure 3F).

Routinely, neurons in the graft were iontophoretically injected with biocytin following electrophysiological recording $(n=3)$. Reconstruction of stained neurons in the graft (Figure 3B) allowed their identification as pyramidal-like neurons, which have been widely described in amygdaloid complex (Yajeya et al., 1997; Sah et al., 2003; Ashenafi et al., 2005) as well as in heterotopic cortical transplants (Senatorov et al., 1991).

\section{DISCUSSION}

It is well known that astrocytes become activated (astrogliosis) in response to different brain lesions such as trauma, stroke, neurons recorded by using sharp electrodes during injection of supra-threshold depolarizing current pulses $(0.3 \mathrm{nA}, 300 \mathrm{~ms})$ showed a regular spiking firing pattern. (D) Spontaneous action potential recorded from a neuron in the graft and a neuron in the basolateral amygdaloid complex. Note the responses similarity. (E) Graft-evoked synaptic current by adjacent host cortex stimulation. Explored neurons presented a facilitation (136 $\pm 22 \%)$ in EPSP amplitude evoked by the second stimulus (S2) presented to the host cortex in relation to the first (S1), at an interval of 50-100 ms. These evoked responses were blocked by $\mathrm{CNQX}(10 \mu \mathrm{M})$ and $\mathrm{APV}(50 \mu \mathrm{M})$ perfusion. (F) Neuron recorded in the graft showing a sustained response to high frequency stimulation of adjacent cortex. This response was removed by atropine sulfate $(1 \mu \mathrm{M})$ perfusion.

tumor, etc. Enhancement of GFAP by reactive astrocytes, is the best known hallmark of reactive astrocytes and reactive gliosis (Soares and McIntosh, 1991). The upregulation of GFAP assists in the reconstruction of broken blood-brain barrier (Smith, 2003), and reactive astrocytes produce various neurotrophic factors that assist neuronal survival. On the other hand, astrogliosis causes formation of glial scar which may inhibit axonal regeneration and neuronal connections (Silver and Miller, 2004). Another possible mechanism has been very recently proposed for repairing injured spinal cord (Goritz et al., 2011), which involves unexpected cells, pericytes, that are needed to regain the tissue integrity, and in the absence of this reaction, holes appear in the tissue instead of scarring. In our study, although we found high GFAP expression in transplant-host interface, we could not discard that this new mechanism was involved in transplant integration. Nevertheless, neurotransmission source to grafted cells was enough to maturate functional pyramidal neurons in the transplant indicating that grafting technique proposed here seems to be so effective that the glial scar can not hinder the nerve connections. Hence, our method might be appropriate for graft integration studies. 
Our findings clearly show that mRNAs from key receptors are continuously present in the transplant (i.e., qualitative equal expression to controls was found). However the amount of mRNA detected in the grafts for each subunit/subtype of receptor was lower than in controls, except for GluR1 and GABAa $\alpha 2$ subunits. Data presented here are the first to use RT-qPCR to show that the three major excitatory/inhibitory receptor types of the nervous system, glutamatergic, GABAergic, and muscarinic receptors, are present in neural transplants. This confirms previous immunohistochemical and electrophysiological studies in cortical transplants showing glutamatergic (Fricker-Gates et al., 2002; Santos-Torres et al., 2009), GABAergic (Fricker-Gates et al., 2002; Santos-Torres et al., 2009), and cholinergic (Jansen et al., 1997; Santos-Torres et al., 2009) receptors and/or neurons in grafted tissue.

It is well established that neuronal circuits require finely balanced neurotransmission for their definitive formation, as neurons normally die, fail to become fully mature, or show alterations in their physiological properties in the absence of their anterograde or retrograde connections. Considering functional integration of the transplant as a consequence of the development of host-graft connections (Castro et al., 1988; Neafsey et al., 1989; Xu et al., 1991; Schulz et al., 1995; Riolobos et al., 2001; Gaillard and Domballe, 2008; Santos-Torres et al., 2009), an adequate synaptic expression of receptors would be needed for restoring connections and lost brain functions following lesions. Therefore, expression of key receptors in the graft, as found here, would be a necessary step to achieve subsequent functional recovery.

As described above embryonic neural grafts placed heterotopically develop a large glial scar 2-3 months after transplantation (Senatorov et al., 1991; Heredia et al., 2004) implying increased number of glial cells and lower neuronal density in the transplant than in the host tissue (see Figure 1A; Petrova and Otellin, 2003). This morphological feature of heterotopic transplants could account for the lower expression levels of most receptor mRNAs found in the graft when compared with both control tissues. In addition, GluR1 and GABAa 2 receptor subunits have been reported to be specifically expressed to a significant extent in glial cells (Bureau et al., 1995; Verkhratsky and Steinhauser, 2000; Douyard et al., 2007).

On the other hand, it has been reported that a traumatic brain lesion induces an increase in glutamatergic neurotransmission and then, cellular death mediated by NMDA receptors. Non-NMDA receptors expression also increases so its attenuation might facilitate to the functional recovery (Schumann et al., 2008). Hence, a smaller amount of AMPA/NMDA differential expression would reduces cellular death probability induced by excitotoxicity and, at the same time, assures to provide an enough neurotransmission source needed for motor function recovery. In addition, it seems quite obvious that if transplant does not become necrotic and its volume increases, it could mainly be due to an enough source of oxygen and glucose caused by an adequate vascularization (Figure 1E).

In order to confirm if functional integration of the transplant had been reached, we also investigated whether transplanted cells from no cortical origin not only develop similar electrophysiological properties to host pyramidal neurons, but also functional synaptic connectivity from the host cortical tissue. Despite extreme difficulty to obtain recordings from heterotopic amygdalar grafts (mainly due to modified physical consistency of the heterotopic grafted tissue caused by the glial scar), we found that transplanted neurons presented membrane and firing properties similar to those neurons from normal/control amygdaloid complex described in vitro (Chapman et al., 1990; Washburn and Moises, 1992; Yajeya et al., 1997, 1999; Ashenafi et al., 2005). In fact, these cells could not be differentiated by their electrophysiological characteristics from normal pyramidal amygdalar neurons recorded in the same preparation. In addition, biocytin-stained neurons presented a pyramidal-like morphology, as previously reported for cortical grafts (Senatorov et al., 1991). Our results therefore suggest that, at the time of analysis, the transplanted cells had reached a degree of maturation that led them to survive and behave like normal pyramidal cells.

Electrical stimulation of adjacent host cortex elicited glutamatergic and muscarinic synaptic responses in grafted cells, confirming our molecular data and suggesting the presence of functional connections between the host and the transplant. Heterotopic amygdalar transplants in cortical locations connect to adjacent cortex and other structures as thalamus as revealed by neuronal tracer biotin dextran amine (BDA) studies (GomezAlvarez et al., unpublished data; Figure A1 in Appendix). This synapse also showed paired pulses facilitation, a synaptic property present in many regions in the brain such as hippocampus (Creager et al., 1980), neocortex (Mercer et al., 2005), or amygdala (Yajeya et al., 2000), that has been related to synaptic plasticity (Nicoll and Malenka, 1999; Madroñal et al., 2009). In addition, the sustained muscarinic response induced in grafted neurons by high frequency stimulation has also been described in amygdala (Washburn and Moises, 1992; Faber and Sah, 2002; Egorov et al., 2006), entorhinal cortex (Egorov et al., 2002), and prefrontal cortex (McCormick et al., 2003), and has been associated with the performance of working memory tasks through recurrent networks. It is well established that persistent activity depends on muscarinic receptors (Major and Tank, 2004; Delgado-Garcia et al., 2006) and it is considered an intrinsic capability for pyramidal neurons in the sensitive and motor cortex (Rahman and Berger, 2011). In addition, cholinergic activity in the motor cortex has been related to synaptic plasticity and motor learning, even showing that a depletion of cholinergic afferents to motor cortex significantly disrupts map plasticity and skilled motor behavior (Conner et al., 2010). The presence of functional cholinergic afferents on transplanted cells might support the idea that transplant itself would be involved in the recovery of previously learned motor functions. These results suggest that synapses are functionally effective within the host-graft circuitry supporting the hypothesis that amygdaloid cells heterotopically transplanted are successfully integrated within the host cortical tissue, as suggested by its behavioral/functional restoration capacity (Heredia et al., 2004).

Finally, it has previously been reported that the closer the genetic programs of graft and host tissues are, the more adequate the influence of the host is (Senatorov et al., 1991). The genetically determined potentialities remain in the transplanted tissues but will only become manifest if all factors provided by the adequate environment are present (Senatorov et al., 1991). In this regard, a common ontogenetic origin for cortical and amygdalar structures 
has been proposed provided by the existence of migrating neurons originating in the ventricular zone of the pallium (cortex) that give rise to the glutamatergic pyramidal neurons within the developing telencephalon (Marin and Rubenstein, 2001). This might explain that grafted amygdalar neural tissue can differentiate into morphologically mature pyramidal neurons assisted by a normal environment supplied by cortical host tissue, receiving functionally effective host projections and exhibiting both normal receptorial expression pattern and electrophysiological properties.

\section{CONCLUSION}

In summary this study shows that neural tissue with a non-motor as well as non-cortical origin (amygdala) might be susceptible to be used in attenuating motor deficits and, therefore offers the possibility of using neural tissue from different lines and origins (maintaining the ontogenetic similarity) to recover motor function following irreversible motor cortical lesions in adults. Furthermore, the fact that the present results have been obtained

\section{REFERENCES}

Ashenafi, S., Fuente, A., Criado, J. M., Riolobos, A. S., Heredia, M., and Yajeya, J. (2005). Beta-Amyloid peptide25-35 depresses excitatory synaptic transmission in the rat basolateral amygdala "in vitro". $\mathrm{Neu}$ robiol. Aging 26, 419-428.

Bureau, M., Laschet, J., Bureau-Heeren, M., Hennuy, B., Minet, A., Wins, P., and Grisar, T. (1995). Astroglial cells express large amounts of GABAA receptor proteins in mature brain. $J$. Neurochem. 65, 2006-2015.

Castro, A. J., Hogan, T. P., Sorensen, J. C., Klausen, B. S., Danielsen, E. H., Zimmer, J., and Neafsey, E. J. (1991). Heterotopic neocortical transplants. An anatomical and electrophysiological analysis of host projections to occipital cortical grafts placed into sensorimotor cortical lesions made in newborn rats. Brain Res. Dev. Brain Res. 58, 231-236.

Castro, A. J., Tonder, N., Sunde, N. A., and Zimmer, J. (1988). Fetal neocortical transplants grafted to the cerebral cortex of newborn rats receive afferents from the basal forebrain, locus coeruleus and midline raphe. Exp. Brain Res. 69, 613-622.

Chapman, P. F., Kairiss, E. W., Keenan, C. L., and Brown, T. H. (1990). Longterm synaptic potentiation in the amygdala. Synapse 6, 271-278.

Chen, G. J., Jeng, C. H., Lin, S. Z., Tsai, S. H., Wang, Y., and Chiang, Y. H. (2002). Fetal striatal transplants restore electrophysiological sensitivity to dopamine in the lesioned striatum of rats with experimental Huntington's disease. J. Biomed. Sci. 9, 303-310.

Conner, J. M., Kulczycki, M., and Tuszynski, M. H. (2010). Unique contributions of distinct cholinergic projections to motor cortical plasticity and learning. Cereb. Cortex 20, 2739-2748.

Creager, R., Dunwiddie, T., and Lynch, G. (1980). Paired-pulse and frequency facilitation in the CAl region of the in vitro rat hippocampus. $J$. Physiol. (Lond.) 299, 409-424.

Delgado-Garcia, J. M., Yajeya, J., and Navarro-Lopez, J. D. (2006). A cholinergic mechanism underlies persistent neural activity necessary for eye fixation. Prog. Brain Res. 154, 211-224.

Douyard, J., Shen, L., Huganir, R. L., and Rubio, M. E. (2007). Differential neuronal and glial expression of GluR1 AMPA receptor subunit and the scaffolding proteins SAP97 and $4.1 \mathrm{~N}$ during rat cerebellar development. J. Comp. Neurol. 502, 141-156.

Egorov, A. V., Hamam, B. N., Fransen, E., Hasselmo, M. E., and Alonso, A. A. (2002). Graded persistent activity in entorhinal cortex neurons. Nature 420, 173-178.

Egorov, A. V., Unsicker, K., and von Bohlen Und, H. O. (2006). Muscarinic control of graded persistent activity in lateral amygdala neurons. Eur. J. Neurosci. 24, 3183-3194.

Escobar, M., Fernandez, J., GuevaraAguilar, R., and Bermudez-Rattoni, F. (1989). Fetal brain grafts induce recovery of learning deficits and connectivity in rats with gustatory neocortex lesion. Brain Res. 478, 368-374.

Faber, E. S., and Sah, P. (2002). Physiological role of calcium-activated potassium currents in the rat lateral amygdala. J. Neurosci. 22, 1618-1628.

Fernandez-Ruiz, J., Escobar, M. L., Pina, A. L., Diaz-Cintra, S., CintraMcGlone, F. L., and BermudezRattoni, F. (1991). Time-dependent

in adult animals (resembling common and difficult clinical scenarios) open new clinical perspectives for brain lesion repair in adulthood, when less synaptic plasticity, more neurodegeneration and delayed functional recovery after ischemic or traumatic surgical lesions is found (Reekmans et al., 2011). Nevertheless, further investigation would be needed to determine the most adequate factors influencing graft integration (Gonzalez-Rey et al., 2010).

\section{ACKNOWLEDGMENTS}

This work was supported by the Spanish Ministry of Science and Innovation (grant number BFU2009-07341, SAF2010-14878); MAPFRE Foundation and Spanish Junta de Castilla y León (grant numbers SA092A08 and SA028A09); Lydia Jiménez-Díaz was supported by Juan de la Cierva Programme and Juan D. Navarro-López by Sara Borrell and Ramón y Cajal Programmes. We acknowledge Dr. S. Morcuende and Dr. S. M. Géranton for enlighten comments and the excellent technical assistance of $\mathrm{N}$. González and J. H. Turrión.

recovery of taste aversion learning by fetal brain transplants in gustatory neocortex-lesioned rats. Behav. Neural Biol. 55, 179-193.

Frappe, I., Roger, M., and Gaillard, A. (1999). Transplants of fetal frontal cortex grafted into the occipital cortex of newborn rats receive a substantial thalamic input from nuclei normally projecting to the frontal cortex. Neuroscience 89, 409-421.

Fricker-Gates, R. A., Shin, J. J., Tai, C. C., Catapano, L. A., and Macklis, J. D. (2002). Late-stage immature neocortical neurons reconstruct interhemispheric connections and form synaptic contacts with increased efficiency in adult mouse cortex undergoing targeted neurodegeneration. $J$. Neurosci. 22, 4045-4056.

Gaillard, A., Gaillard, F., and Roger, M. (1998). Neocortical grafting to newborn and adult rats: developmental, anatomical and functional aspects. Adv. Anat. Embryol. Cell Biol. 148, 1-86.

Gaillard, A., Prestoz, L., Dumartin, B., Cantereau, A., Morel, F., Roger, M., and Jaber, M. (2007). Reestablishment of damaged adult motor pathways by grafted embryonic cortical neurons. Nat. Neurosci. 10, 1294-1299.

Gaillard, F., and Domballe, L. (2008). Fetal tissue allografts in the damaged adult visual cortex: physiology and connectivity. Restor. Neurol. Neurosci. 26, 267-277.

Garcia-Lopez, M., Abellán, A., Legaz, I., Rubenstein, J. L., Puelles, L. and Medina, L. (2008). Histogenetic compartments of the mouse centromedial and extended amygdala based on gene expression patterns during development. J. Comp. Neurol. 506, 46-74.
Gonzalez-Rey, E., Delgado-Maroto, V., Souza, M. L., and Delgado, M. (2010). Neuropeptides as therapeutic approach to autoimmune diseases. Curr. Pharm. Des. 16, 3158-3172.

Goritz, C., Dias, D. O., Tomilin, N., Barbacid, M., Shupliakov, O., and Frisen, J. (2011). A pericyte origin of spinal cord scar tissue. Science 333, 238-242.

Heredia, M., Riolobos, A. S., Criado, J. M., Fuente, A., and Yajeya, J. (2004). Recovery of motor deficits by fetal amygdaloid grafts. FENS Abstr. 2, A025.7.

Jansen, E. M., Solberg, L., Underhill, S., Wilson, S., Cozzari, C., Hartman, B. K., Faris, P. L., and Low, W. C. (1997). Transplantation of fetal neocortex ameliorates sensorimotor and locomotor deficits following neonatal ischemic-hypoxic brain injury in rats. Exp. Neurol. 147, 487-497.

Labbe, R., Firl, A. Jr., Mufson, E. J., and Stein, D. G. (1983). Fetal brain transplant: reduction of cognitive deficits in rats with frontal cortex lesions. Science 221, 470-472.

Madroñal, N., Gruart, A., and gadoGarcia, J. M. (2009). Differing presynaptic contributions to LTP and associative learning in behaving mice. Front. Behav. Neurosci. 3:7. doi:10.3389/neuro.08.007.2009

Major, G., and Tank, D. (2004). Persistent neural activity: prevalence and mechanisms. Curr. Opin. Neurobiol. 14, 675-684.

Malkoff, A., Weizman, A., Gozes, I., and Rehavi, M. (2008). Decreased M1 muscarinic receptor density in rat amphetamine model of schizophrenia is normalized by clozapine, but not haloperidol. J. Neural Transm. 115, 1563-1571. 
Marin, O., and Rubenstein, J. L. (2001). A long, remarkable journey: tangential migration in the telencephalon. Nat. Rev. Neurosci. 2, 780-790.

McCormick, D. A., Shu, Y., Hasenstaub, A., Sanchez-Vives, M., Badoual, M., and Bal, T. (2003). Persistent cortical activity: mechanisms of generation and effects on neuronal excitability. Cereb. Cortex 13, 1219-1231.

Medina, L., Legaz, I., González, G., De Castro, F., Rubenstein, J. L., and Puelles, L. (2004). Expression of Dbx1, Neurogenin 2, Semaphorin 5A, Cadherin 8, and Emxl distinguish ventral and lateral pallial histogenetic divisions in the developing mouse claustroamygdaloid complex. J. Comp. Neurol. 474, 504-523.

Mercer, A., West, D. C., Morris, O. T., Kirchhecker, S., Kerkhoff, J. E., and Thomson, A. M. (2005). Excitatory connections made by presynaptic cortico-cortical pyramidal cells in layer 6 of the neocortex. Cereb. Cortex 15, 1485-1496.

Neafsey, E. J., Sorensen, J. C., Tonder, N., and Castro, A. J. (1989). Fetal cortical transplants into neonatal rats respond to thalamic and peripheral stimulation in the adult. An electrophysiological study of single-unit activity. Brain Res. 493, 33-40.

Nicoll, R. A., and Malenka, R. C. (1999). Expression mechanisms underlying NMDA receptor-dependent longterm potentiation. Ann. N. Y. Acad. Sci. 868, 515-525.

Petrova, E. S., and Otellin, V. A. (2003). Degenerative changes and cell death in long-living homo- and heterotopic transplants from embryonic germ layers of rat neocortex. Bull. Exp. Biol. Med. 136, 302-306.

Pfaffl, M. W. (2001). A new mathematical model for relative quantification in real-time RT-PCR. Nucleic Acids Res. 29, e45.

Picard, N., Guenin, S., Larnicol, N., and Perrin, Y. (2008). Maternal caffeine ingestion during gestation and lactation influences respiratory adaptation to acute alveolar hypoxia in newborn rats and adenosine $\mathrm{A} 2 \mathrm{~A}$ and GABA A receptor mRNA transcription. Neuroscience $156,630-639$.

Plumet, J., Cadusseau, J., and Roger, M. (1991). Skilled forelimb use in the rat: amelioration of functional deficits resulting from neonatal damage to the frontal cortex by neonatal transplantation of fetal cortical tissue. Restor. Neurol. Neurosci. 3, 135-147.
Plumet, J., Ebrahimi, A., and Roger, M. (1993). Partial recovery of skilled forelimb reaching after transplantation of fetal cortical tissue in adult rats with motor cortex lesion. Anatomical and functional aspects. Restor. Neurol. Neurosci. 6, 9-27.

Puelles, L., Kuwana, E., Puelles, E., Bulfone, A., Shimamura, K., Keleher, J., Smiga, S., and Rubenstein, J. L. (2000). Pallial and subpallial derivatives in the embryonic chick and mouse telencephalon, traced by the expression of the genes Dlx-2, Emx-1, Nkx-2.1, Pax6, and Tbr-1. J. Comp. Neurol. 424, 409-438.

Rahman, J., and Berger, T. (2011). Persistent activity in layer 5 pyramidal neurons following cholinergic activation of mouse primary cortices. Eur. J. Neurosci. 34, 22-30.

Reekmans, K., Praet, J., Daans, J., Reumers, V., Pauwels, P., Van der Linden, A., Berneman, Z. N., and Ponsaerts, P. (2011). Current challenges for the advancement of neural stem cell biology and transplantation research. Stem Cell Rev. doi: 10.1007/s12015-011-9266-2. [Epub ahead of print].

Riolobos, A. S., Heredia, M., de la Fuente, A., Criado, J. M., Yajeya, J., Campos, J., and Santacana, M. (2001). Functional recovery of skilled forelimb use in rats obliged to use the impaired limb after grafting of the frontal cortex lesion with homotopic fetal cortex. Neurobiol. Learn. Mem. 75, 274-292.

Roger, M., and Ebrahimi-Gaillard, A. (1994). Anatomical and functional characteristics of fetal neocortex transplanted into the neocortex of newborn or adult rats. Rev. Neurosci. 5, 11-26.

Sah, P., Faber, E. S., Lopez De, A. M., and Power, J. (2003). The amygdaloid complex: anatomy and physiology. Physiol. Rev. 83, 803-834.

Santos-Torres, J., Heredia, M., Riolobos, A. S., Jimenez-Diaz, L., GomezBautista, V., de la Fuente, A., Criado, J. M., Yajeya, J., and NavarroLopez, J. (2009). Electrophysiological and synaptic characterization of transplanted neurons in adult rat motor cortex. J. Neurotrauma 26, 1593-1607.

Schulz, M. K., McNulty, J. A., Handa, R. J., Hogan, T. P., Tillotson, G. L., Shaw, P. L., Zimmer, J., and Castro, A. J. (1995). Fetal neocortical transplants grafted into neocortical lesion cavities made in newborn rats: an analysis of transplant integration with the host brain. Cell Transplant. 4, 123-132.

Schumann, J., Alexandrovich, G. A., Biegon, A., and Yaka, R. (2008). Inhibition of NR2B phosphorylation restores alterations in NMDA receptor expression and improves functional recovery following traumatic brain injury in mice. J. Neurotrauma 25, 945-957.

Segal, M., and Azmitia, E. C. (1986) Fetal raphe neurons grafted into the hippocampus develop normal adult physiological properties. Brain Res. 364, 162-166.

Senatorov, V. V., Obuhova, G. P., and Fulop, Z. (1991). Electrophysiologi$\mathrm{cal}$ and morphological properties of embryonic neocortical grafts developing in different regions of the host rat brain. J. Neural Transplant. Plast. 2, 125-140.

Silver, J., and Miller, J. H. (2004). Regeneration beyond the glial scar. Nat. Rev. Neurosci. 5, 146-156.

Smith, Q. R. (2003). A review of bloodbrain barrier transport techniques. Methods Mol. Med. 89, 193-208.

Soares, H., and McIntosh, T. K. (1991). Fetal cortical transplants in adult rats subjected to experimental brain injury. J. Neural Transplant. Plast. 2 , 207-220.

Sorensen, J. C., Zimmer, J., and Castro, A. J. (1989). Fetal cortical transplants reduce the thalamic atrophy induced by frontal cortical lesions in newborn rats. Neurosci. Lett. 98 , 33-38.

Su, H., Zhang, W., Guo, J., Guo, A., Yuan, Q., and Wu, W. (2009). Neural progenitor cells enhance the survival and axonal regeneration of injured motoneurons after transplantation into the avulsed ventral horn of adult rats. J. Neurotrauma 26, 67-80.

Thompson, L., Barraud, P., Andersson, E., Kirik, D., and Bjorklund, A. (2005). Identification of dopaminergic neurons of nigral and ventral tegmental area subtypes in grafts of fetal ventral mesencephalon based on cell morphology, protein expression, and efferent projections. $J$. Neurosci. 25, 6467-6477.

Verkhratsky, A., and Steinhauser, C. (2000). Ion channels in glial cells. Brain Res. Brain Res. Rev. 32, 380-412.

Washburn, M. S., and Moises, H. C. (1992). Muscarinic responses of rat basolateral amygdaloid neurons recorded in vitro. J. Physiol. (Lond.) $449,121-154$

Xu, Z. C., Wilson, C. J., and Emson, P. C. (1991). Synaptic potentials evoked in spiny neurons in rat neostriatal grafts by cortical and thalamic stimulation. J. Neurophysiol. 65 , 477-493.

Yajeya, J., de la Fuente, A., Criado, J. M., Bajo, V., Sanchez-Riolobos, A., and Heredia, M. (2000). Muscarinic agonist carbachol depresses excitatory synaptic transmission in the rat basolateral amygdala in vitro. Synapse 38, 151-160.

Yajeya, J., de la Fuente, J. A., Bajo, V. M., Riolobos, A. S., Heredia, M., and Criado, J. M. (1999). Muscarinic activation of a nonselective cationic conductance in pyramidal neurons in rat basolateral amygdala. Neuroscience 88 , 159-167.

Yajeya, J., de la Fuente, J. A., Merchan, M. A., Riolobos, A. S., Heredia, M., and Criado, J. M. (1997). Cholinergic responses of morphologically and electrophysiologically characterized neurons of the basolateral complex in rat amygdala slices. Neuroscience $78,731-743$.

Zhou, W., Raisman, G., and Zhou, C. (1998). Transplanted embryonic entorhinal neurons make functional synapses in adult host hippocampus. Brain Res. 788, 202-206.

Conflict of Interest Statement: The authors declare that the research was conducted in the absence of any commercial or financial relationships that could be construed as a potential conflict of interest.

Received: 22 May 2011; accepted: 29 August 2011; published online: 15 September 2011

Citation: Jiménez-Díaz L, Nava-Mesa MO, Heredia M, Riolobos AS, GómezÁlvarez $M$, Criado $J M$, de la Fuente A, Yajeya $J$ and Navarro-López JD (2011) Embryonic amygdalar transplants in adult rats with motor cortex lesions: a molecular and electrophysiological analysis. Front. Neur. 2:59. doi: 10.3389/fneur.2011.00059

This article was submitted to Frontiers in Neurotrauma, a specialty of Frontiers in Neurology.

Copyright (ㅇ) 2011 Jiménez-Díaz, Nava-Mesa, Heredia, Riolobos, GómezÁlvarez, Criado, de la Fuente, Yajeya and Navarro-López. This is an open-access article subject to a non-exclusive license between the authors and Frontiers Media $S A$, which permits use, distribution and reproduction in other forums, provided the original authors and source are credited and other Frontiers conditions are complied with. 


\section{APPENDIX}
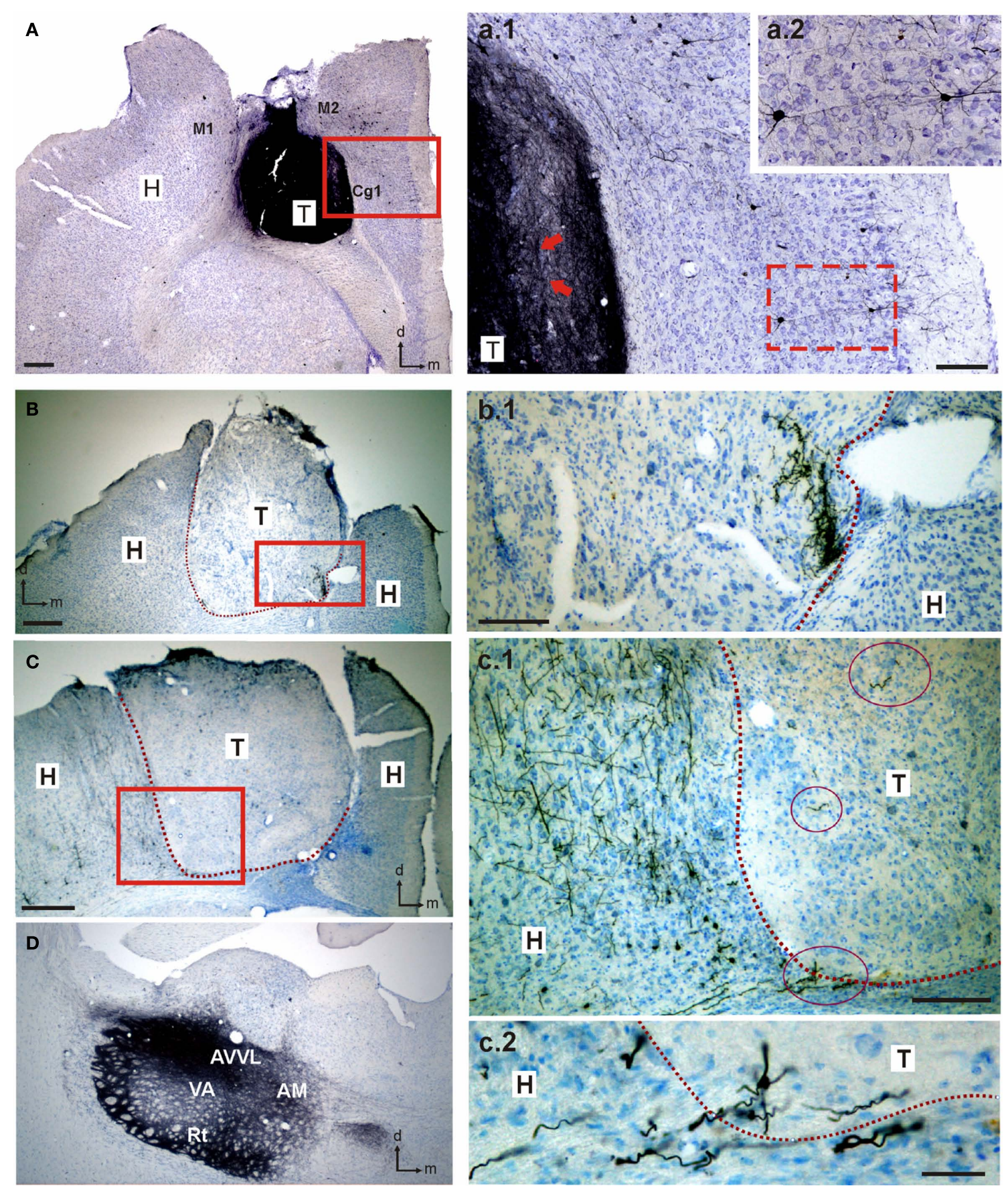

FIGURE A1 | Heterotopic amygdalar transplants in cortical locations connect to adjacent cortex and other structures as thalamus. Connections between the transplant and the host tissue were revealed by neuronal tracer biotin dextran amine (BDA) injections performed in either the graft $(\mathbf{A}, \mathbf{a} . \mathbf{1}, \mathbf{a . 2})$ or ventral and dorsal nuclei of the thalamus (B,b.1,C,c.1,c.2,D). Eight days after BDA injections, animals were perfused and tissue was cut in $40 \mathrm{~lm}$ sections; BDA was visualized with a diaminobenzidine/hydrogen peroxide solution, and sections were then counterstained with cresyl fast violet. (A) Photomicrograph of a coronal section through a heterotopic cortical transplant of embryonic amygdalar tissue. BDA was injected into the transplant. BDA-labeled neurons in the host tissue are shown in $\mathbf{( a . 1 , a . 2 )}$ at higher magnification [red squares in (A,a.1)]. BDA-labeled fibers within the graft can also be observed in (a.1) (red arrows). (B,C) Photomicrographs of coronal sections through two amygdalar transplants placed heterotopically in motor cortical location. Red squares shows BDA-labeled fibers in the host and the transplant at higher magnification (b.1,c.1). Dashed lines indicate transplant-host interface. Red ovals in (c.1) indicate labeled fibers within the transplant or transplant edge. One of these fibers is illustrated at higher magnification in (c.2). (D). Photomicrograph of a coronal section through the BDA injection site in the thalamus. AVVL, anteroventral thalamic nucleus, ventral part; AM, anteromedial thalamic nucleus; $\mathrm{Cg} 1$, cingulated cortex, area 1; H, host; M1, primary motor cortex; M2, secondary motor cortex; Rt, reticular thalamic nucleus; T, transplant; VA, ventral anterior thalamic nucleus. Scale bars, (A-C): $250 \mu \mathrm{m}$; (a.1,b.1,c.1): $100 \mu \mathrm{m}$; (c.2): $20 \mu \mathrm{m}$. 